\title{
A matter of timing: microRNA-controlled temporal identities in worms and flies
}

\author{
Manfred Frasch ${ }^{1}$ \\ Department Biology, Developmental Biology Unit, University of Erlangen-Nürnberg, Erlangen, 91058 Erlangen, Germany
}

\begin{abstract}
The first microRNAs were identified in Caenorhabditis elegans based on their functions in the temporal regulation of stage-specific cell fate decisions. Until now, it was not known whether the so-called heterochronic genes that encode miRNAs are also involved in controlling developmental transitions in other organisms. New findings by Sokol et al. (this issue of Genes \& Development, pp. 1591-1596) demonstrate that the Drosophila counterpart of a heterochronic miRNA gene from $C$. $e$ legans, let-7, does indeed play a role in promoting stagespecific developmental events in neuromuscular tissues during the transition from larval to adult stages, thus pointing to a more widespread utilization of miRNAs in temporal regulation of animal development.
\end{abstract}

In order to build a normal animal, the development of individual tissues and organs needs to be tightly coordinated with the developmental progression of the whole organism. This point is particularly obvious in species that go through well-defined developmental stages, as is the case for the molting stages and metamorphosis in Ecdysozoans. For this reason, and the power of genetics, developmental timing mechanisms have been dissected particularly well in the Ecdysozoan model organisms Caenorhabditis elegans and Drosophila. Before the question of the coordination of developmental events could be addressed, it was first necessary to ask two more basic questions: First, how is the developmental progression of the whole organism controlled and how are the temporal boundaries of the distinct stages set? And second, how does the organism know which cell types and tissues need to be generated or abolished during a particular time period?

Past research has provided partial answers to both of these questions and defined genes and regulatory pathways that control each of these aspects. Conceptually, genes that affect temporal boundaries have been likened to segmentation genes in insects, which subdivide the early embryo spatially. Likewise, genes affecting the

[Keywords: let-7; let-7-Complex; microRNA; heterochronic; developmental timing; neuromuscular junction]

${ }^{1}$ Correspondence.

E-MAIL manfred.frasch@biologie.uni-erlangen.de; FAX 49-9131-8528040. Article is online at http://www.genesdev.org/cgi/doi/10.1101/gad.1690608. temporal identities of body parts have been likened to homeotic genes, which provide each body part with its proper spatial identity (Ambros and Horvitz 1987; Slack and Ruvkun 1997; Thummel 2001). Surprisingly, temporal boundary genes have been described almost exclusively in flies, but not in worms. However, temporal identity genes (heterochronic genes) have long been discovered in worms, but only very recently in flies (for review, see Thummel 2001; Banerjee and Slack 2002; Moss 2007; Yu and Lee 2007). This dichotomy is partially explained by the historic approaches that have been taken to address these questions as well as by the particular strengths of each of the two systems. In flies and moths, the genetic approach was preceded by an endocrinological approach, which established the key roles of steroid hormone signaling in the global regulation of post-embryonic timing events. In contrast, in C. elegans the presence of defined cell lineages, in which specific cell divisions within each molting stage are normally linked to specific cell fate decisions, allowed the identification of so-called heterochronic mutations. In these mutations, the identities of daughter cells in a particular lineage and time point are transformed into identities of cells that are supposed to appear later in development or have already appeared at an earlier time point. Hence, particular steps within the lineage are either skipped or duplicated, thus leading to asynchrony of the lineage progression and global development with respect to the molting stage. In Drosophila, a number of temporal boundary genes have been defined genetically and molecularly that execute the program triggered by steroid hormone signals, whereas in C. elegans, numerous temporal identity genes have been isolated that are linked to heterochronic phenotypes. Consequently, until now it was only possible to speculate about the potential connections of these two temporal programs and the genes that are involved. Moreover, based on these data it has been far from obvious whether temporal regulation of development in C. elegans and Drosophila utilizes related principles and mechanisms. The study by Sokol et al. (2008) in the current issue presents important advances that are likely to change this situation. In essence, Sokol et al. (2008) demonstrate that let-7, a Drosophila ortholog of the heterochronic let-7 gene from $C$. elegans, has heterochronic phenotypes in Drosophila. Notably, Drosophila let-7 has been linked previously to 
the hormone-dependent developmental program. Together, these findings open an avenue to integrate the mechanisms for regulating temporal boundaries and temporal identities during animal development, at least in Ecdysozoans.

\section{let-7 and interacting heterochronic genes in C. elegans}

C. elegans larvae undergo four molting stages, L1 through L4, prior to adulthood. Among other features, each of these stages is characterized by defined cell-division patterns in the epidermis that generate the adult seam cells, which have been convenient for identifying and characterizing the functions of heterochronic genes. let-7 is one of the key genes in this pathway of temporal identity specification and was found to act in the late phase of the program (for review, see Banerjee and Slack 2002; Moss 2007). In let-7 mutants, the L4-specific cell division pattern is inappropriately reiterated upon transitioning into the adult stage. Fittingly, let-7 RNA expression is observed in the epidermis from the beginning of L4 into the adult stage. Upon forced premature expression of let-7 the converse phenotype is observed, which consists of precocious formation of adult epidermal features during L4 (Hayes and Ruvkun 2006). Altogether, these genetic data demonstrate that let-7 is a temporal identity gene that normally guides the proper shift of epidermal identities during the transition from L4 to the adult stage.

let-7 and lin-4, an earlier-acting heterochronic gene, were founding members of the class of microRNA-encoding genes. miRNAs consist of $\sim 22$ nucleotide noncoding RNAs that down-regulate target genes by binding to sites with partial complementarity in the $3^{\prime}$ UTR (and potentially 5 ' UTR) (Lytle et al. 2007) of their transcripts, which leads to translational inhibition and sometimes mRNA degradation (Bagga et al. 2005; Stefani and Slack 2008). For let-7 miRNAs, targets have first been identified as heterochronic genes that interact genetically with let-7 (for review, see Banerjee and Slack 2002; Moss 2007). A key target among these in the epidermis is lin41 , which encodes a cytoplasmic protein of the RBCC/ TRIM/NHL protein family. Although lin- 41 mRNA is expressed throughout the larval stages, LIN-41 protein levels are down-regulated at the end of L3, when let-7 miRNAs start accumulating. Indeed, let-7 is required for down-regulating LIN-41, and this involves direct binding of let-7 to two let-7 complementary sites (LCSs) in the $3^{\prime}$ UTR of lin-41 mRNA that are necessary, and in the context of the entire 3' UTR sufficient, to mediate translational repression (Vella et al. 2004). Mutation of lin-41 alone causes a precocious phenotype during L3. Importantly, lin-41 mutation can partially suppress the let-7 mutant phenotype, thus suggesting that a major role of let-7 in the epidermis is to down-regulate lin-41 protein levels (Reinhart et al. 2000). This down-regulation is essential for allowing the accumulation of LIN-29, a Krüppel-family zinc finger transcription factor encoded by the most downstream member of heterochronic genes in this pathway. LIN-29 triggers the terminal switch to adult fates (Rougvie and Ambros 1995; Slack et al. 2000). Another major target of let-7 in this pathway of temporally regulated seam cell development is daf-12, which encodes a nuclear hormone receptor (Antebi et al. 2000). daf-12 knockdown enhances the precocious phenotype of lin-41 knockdown, suggesting that it normally cooperates with lin-41 to prevent premature differentiation. Conversely, a daf-12-null mutation strongly suppresses let-7 lethality, which suggests that down-regulation of DAF-12 (together with LIN-41) by let-7 in epidermal cells is an important prerequisite for normal progression of epidermal development during the late phase of the differentiation pathway. Again, let-7 seems to act through LCSs in the $3^{\prime}$ UTR of daf-12 to exert its negative effects (Grosshans et al. 2005).

Clearly, let-7 has other targets besides lin-41 and daf12 that need to be down-regulated in order to control proper temporal identities. Several candidates have already been found based on genetic interactions or, as in the case of daf-12, by the presence of LCSs in their 3' UTRs, and have been verified by additional experiments. let-7 is known to target the mRNA products of some of these genes, through their LCS-containing $3^{\prime}$ UTRs, in a tissue-specific manner. For example, hbl-1, which encodes a zinc finger transcription factor that is related to Drosophila hunchback, is particularly down-regulated by let-7 in neurons, whereas the forkhead domain-encoding gene pha-4 is down-regulated in the intestine during late larval stages (Abrahante et al. 2003; Lin et al. 2003; Grosshans et al. 2005).

Altogether, a picture has emerged in which temporal identity genes, such as let-7, act as "master regulators" that trigger critical developmental transitions simultaneously in several different tissues. To achieve this, let-7 needs to down-regulate specific targets that are shared among different tissues (such as lin-41 in epidermal and neuronal cells), whereas others are targeted by let-7 in a tissue-specific fashion. An additional extension of the regulatory network is provided by the action of other members of the let-7 family of miRNAs, which can act on some of the same targets (including hbl-1), but with different stage- and perhaps tissue-specific activities (Abbott et al. 2005). A key question that is yet to be answered is how the transcription of these heterochronic miRNA genes is regulated temporally and integrated into the ordered progression of this pathway.

\section{Temporal boundaries and the remodeling of the musculature in Drosophila}

In Drosophila, the ordered progression of the molting stages and of metamorphosis is dominated by systemic hormone signals. The temporal boundaries are set by pulses of the steroid hormone ecdysone, which occur just prior to each molt and during two critical phases of metamorphosis (for review, see Thummel 2001). The timing mechanisms for these pulses are believed to be linked to the circadian rhythm and growth status through the release and action of endocrine signals, including the neuropeptide prothoracicotropic hormone 
(PTTH) and insulin (Caldwell et al. 2005; Colombani et al. 2005; McBrayer et al. 2007). Much more information is available about the mechanisms that transmit and execute the developmental program downstream from the ecdysone pulses, particularly with regard to the salivary glands and the pulses that trigger the transitions from the last larval (L3) to the prepupal, and from the prepupal to the pupal stages (for review, see Thummel 2001). In brief, the late larval pulse directly activates specific primary response genes via binding of the ecdysone/ecdysone receptor/RXR (aka Usp) complexes to their regulatory sequences. Some of the primary response genes, such as those of the Broad Complex $(B r-C)$ and E74, which encode zinc finger and ETS domain transcription factors, respectively, directly activate or repress secondary response genes that participate in appropriate differentiation events in the salivary glands. Three other primary response genes, E75B,DHR, and $\beta F T Z-F 1$, which encode different nuclear receptors, form a temporal relay through a cascade of positive (for $E 75 B$ and $D H R 3$ ) and negative (for $\beta F t z-F 1$ ) regulation by the ecdysone receptor complexes, in combination with repressive or activating cross-regulatory interactions among these genes. This provides a timing mechanism in which $\beta F T Z-F 1$ is induced later and remains expressed during the following ecdysone pulse in late prepupae, where it is needed to modify the activities of the newly induced $B R-C$ and $E 74 A$ transcription factors. As a consequence, these factors promote pupal-specific events during this transition. Hence, $\beta F T Z$-F1 can be considered as a temporal identity gene in Drosophila, whereas the ecdysone receptor and usp genes function as temporal boundary genes.

A key event in the salivary gland, as well as in other larval tissues such as the midgut and muscles, during early pupal stages, is programmed cell death, which allows the removal of larval tissues and their replacement by the corresponding adult tissues. This pathway is induced as a response to ecdysone through the combined actions of $B R-C, E 74 A$, and $\beta F T Z-F 1$ during these stages, which in turn activate transcription of the $E 93$ gene that encodes a nuclear factor that is directly involved in triggering cell death (Lee et al. 2000). This function entails the transcriptional activation of genes for proapoptotic factors, such as the apical caspase Dronc and the antagonists of the apoptotic inhibitor DIAP1, Reaper, and Hid. $D I A P 1$ needs to be down-regulated transcriptionally as well, which happens during the previous pulse (Lee et al. 2000; Daish et al. 2003; Yin et al. 2007). In addition, genes that promote autophagy of salivary glands are induced in the salivary gland and are crucial for the process of tissue degradation in cooperation with the proapoptotic activities (for review, see Yin and Thummel 2005; Berry and Baehrecke 2007).

During the period between the pupal stage and the newly hatched adults, massive rebuilding also takes place in the body wall musculature and, concomitantly, the neuromuscular junctions. This process must also be integrated with the steroid signaling program, although the details are not yet known. The changeover from the larval to the adult muscle pattern is executed via two different processes (for review, see Roy and VijayRaghavan 1999). One process, which thus far has only been observed for a subset of indirect flight muscles in the thorax, utilizes unhistolyzed larval muscle fibers as scaffolds, to which imaginal myoblasts from the wing imaginal discs fuse. This leads to increases in size, and in connection with the splitting of these fibers, to duplications and characteristic shape changes. The second process, which applies to the majority of thoracic and abdominal muscles, involves total degradation of the larval muscles and de novo formation of adult muscles through the fusion of imaginal muscle founder myoblasts and fusion-competent myoblasts. Interestingly, not all of the doomed larval muscles are degraded during the same stage. Instead, a subset of abdominal intersegmental muscles, which are the subject of the current study by Sokol et al. (2008) and are called dorsal internal oblique muscles (DIOMs), are first remodeled during metamorphosis because they are needed for the hatching of the fly from the pupal case and are only then degraded after having fulfilled this job (Kimura and Truman 1990). Based on observations with analogous muscles in moths, this degradation is probably also accomplished through autophagy (Jones and Schwartz 2001). The prolonged maintenance and eventual breakdown of these muscles are obviously connected to the steroid hormone-dependent temporal regulation program. Their competence for degradation is also known to require hormonal or neuroendocrine signals from the head or thorax that are released prior to eclosion. In addition, degradation of these muscles depends on behavioral feedbacks, because forced confinement of the flies within the pupal case results in a significant delay of muscle breakdown (Kimura and Truman 1990). Hence, this process could serve as a model for studying stage-specific tissue remodeling that requires the integration of activities of temporal boundary genes with those of temporal identity genes and behavioral signals.

\section{Conserved temporal identity and boundary regulators in worms and flies?}

So, are the developmental processes during the molting stages and metamorphosis controlled by completely different timing mechanisms in worms and flies? Perhaps not. The fact that the heterochronic worm gene daf-12 encodes a nuclear hormone receptor family member, which seems to require a steroid hormone, and that nhr25 , the worm ortholog of $\beta F t z-F 1$, is also required for larval molting, provide intriguing hints for a possible link between the role of heterochronic miRNAs and steroid hormone signaling in C. elegans, even though ecdysone itself and its receptors are absent (for review, see Thummel 2001; Antebi 2006). Even more remarkable is the wide evolutionary conservation of heterochronic miRNA genes in bilaterians, including Drosophila, which has miRNA genes that are closely related to let-7 (also called let-7) and lin-4 (called miR-125) (Pasquinelli et al. 2000; Lagos-Quintana et al. 2002). In flies, these two miRNAs are actually generated from a common pri- 
mary transcript, which includes a third miRNA, miR-100, and thus all three are coexpressed spatially and temporally. Similar to C. elegans, the expression of Drosophila let-7 is also initiated during the larval-to-adult transition. The temporal profile closely correlates with ecdysone-triggered responses during the onset of metamorphosis, where let-7 (and its "sibling" miRNAs) starts to be expressed during the peak of $E 74$ expression and accumulates further during pupation (Sempere et al. 2002, 2003; Bashirullah et al. 2003). Indeed, there are data that indicate that the let-7-Complex (let-7-C) is induced downstream from ecdysone and $B R-C$ genes, although there are also conflicting results that may suggest that the induction occurs through a different hormone pathway that acts in parallel to ecdysone (Sempere et al. 2002, 2003; Bashirullah et al. 2003).

All of these findings raise the urgent question of whether let-7 and miR125/lin-4 also function as temporal identity genes, and therefore act as heterchronic genes during the larval-to-adult transition in Drosophila. This is where the study by Sokol et al. (2008) provides an important step forward. The investigators generated a knockout of the let-7-C locus and showed through rescue experiments that the described phenotypes are caused specifically by loss of let-7.

let-7 knockout flies are viable but show behavioral defects, which can be attributed, at least to a significant degree, to heterochronic phenotypes in neuromuscular tissues. First, the aforementioned DIOM muscles persist in the adults indefinitely instead of being degraded $\sim 12 \mathrm{~h}$ after eclosure. Second, the newly formed intersegmental dorsal muscles (DMs) fail to complete their larval-toadult remodeling and remain smaller than normal, because fewer myoblasts contribute to the syncytia. Third, the neuromuscular junctions of the DIOMs that normally decay along with their motoneurons (but in a process largely independent from the DIOMs) also persist. In addition, neuromuscular junctions at the DMs are either absent or immature. As proposed by Sokol et al. (2008) these phenotypes can be viewed as heterochronic because "juvenile" features in neuromuscular tissues are present in the mature adult. Of note, these tissue-specific phenotypes are correlated with the observed restricted expression of let-7-C in the muscles and neurons of the ventral nerve cord during these stages.

These findings open up new avenues and raise some interesting questions. (1) How is the expression and function of let-7 integrated into the hormonal programs in Drosophila? For clarification, additional studies could now include the dissection of enhancers and potential binding sites for hormone-dependent trans-acting factors of let-7-C. (2) How is the exact timing of let-7-dependent DIOM degradation during early adult stages controlled if let-7 expression is already initiated much earlier, namely during the prepupal-to-pupal transition? The identification of let-7 targets could help resolve this issue. In addition to muscle-intrinsic targets, they may include genes that are important for the release of the head-derived signals that are already needed during pupal stages to allow the later degradation of these muscles (Kimura and Truman 1990). Indeed, perhaps the most burning question is: (3) What are the key targets of let-7 that are responsible for the observed phenotypes and how many functional targets are there? Are some of the targets directly involved in triggering the apoptotic or autophagic pathway or are the relevant targets acting further upstream? Are targets involved that correspond to the ones that have already been defined as let- 7 targets in $C$. elegans? For the most part, the predicted targets of Drosophila let-7 differ from those predicted for C. elegans let-7 (Grun et al. 2005; Lall et al. 2006). However, a recent study showed that a Drosophila lin-41 homolog is a likely target of $1 e t-7$, a possibility that can now be tested more rigorously with the newly available materials (O'Farrell et al. 2008). Sokol et al. (2008) cite unpublished observations indicating that abrupt, which encodes a BTB-domain transcription factor, may be a functional let-7 target. This is intriguing, as abrupt is, at least in embryos, expressed in muscles and required for the establishment of proper neuromuscular junctions $(\mathrm{Hu}$ et al. 1995). (4) Are there additional, yet undetected heterochronic or other phenotypes that can be attributed to let-7 or its sibling miRNAs, miR-100 and miR-125/lin4? (5) Do other miRNA family members have partially redundant functions, or do miRNAs exert relatively minor roles in defining temporal identities in Drosophila as indicated by the viability of the mutants? In addition to allowing these questions to be addressed in the Drosophila system, the findings by Sokol et al. (2008) will also renew the interest in the question of how heterochronic gene action is integrated into possible hormonal programs in C. elegans. Finally, they beg the question of whether the counterparts of let-7 and other heterochronic miRNAs known from $C$. elegans have more widely conserved roles in regulating developmental transitions not only in Drosophila, but also in other bilaterian organisms.

\section{Acknowledgments}

I thank Dr. Hank T. Nguyen for critical review of the manuscript. I also acknowledge research support from the National Institutes of Health.

\section{References}

Abbott, A.L., Alvarez-Saavedra, E., Miska, E.A., Lau, N.C., Bartel, D.P., Horvitz, H.R., and Ambros, V. 2005. The let-7 microRNA family members mir-48, mir-84, and mir-241 function together to regulate developmental timing in Caenorhabditis elegans. Dev. Cell 9: 403-414.

Abrahante, J.E., Daul, A.L., Li, M., Volk, M.L., Tennessen, J.M., Miller, E.A., and Rougvie, A.E. 2003. The Caenorhabditis elegans hunchback-like gene lin-57/hbl-1 controls developmental time and is regulated by microRNAs. Dev. Cell 4: 625-637.

Ambros, V. and Horvitz, H.R. 1987. The lin-14 locus of Caenorhabditis elegans controls the time of expression of specific postembryonic developmental events. Genes \& Dev. 1: 398-414.

Antebi, A. 2006. Nuclear hormone receptors in C. elegans (January 03, 2006). In WormBook (ed. The C. elegans Research 
Community) WormBook, doi: 10.1895/wormbook.1.64.1, http://www.wormbook.org.

Antebi, A., Yeh, W.H., Tait, D., Hedgecock, E.M., and Riddle, D.L. 2000. daf-12 encodes a nuclear receptor that regulates the dauer diapause and developmental age in C. elegans. Genes \& Dev. 14: 1512-1527.

Bagga, S., Bracht, J., Hunter, S., Massirer, K., Holtz, J., Eachus, R., and Pasquinelli, A.E. 2005. Regulation by let-7 and lin-4 miRNAs results in target mRNA degradation. Cell 122: 553-563.

Banerjee, D. and Slack, F. 2002. Control of developmental timing by small temporal RNAs: A paradigm for RNA-mediated regulation of gene expression. Bioessays 24: 119-129.

Bashirullah, A., Pasquinelli, A.E., Kiger, A.A., Perrimon, N., Ruvkun, G., and Thummel, C.S. 2003. Coordinate regulation of small temporal RNAs at the onset of Drosophila metamorphosis. Dev. Biol. 259: 1-8.

Berry, D.L. and Baehrecke, E.H. 2007. Growth arrest and autophagy are required for salivary gland cell degradation in Drosophila. Cell 131: 1137-1148.

Caldwell, P.E., Walkiewicz, M., and Stern, M. 2005. Ras activity in the Drosophila prothoracic gland regulates body size and developmental rate via ecdysone release. Curr. Biol. 15: 1785-1795.

Colombani, J., Bianchini, L., Layalle, S., Pondeville, E., Dauphin-Villemant, C., Antoniewski, C., Carre, C., Noselli, S., and Leopold, P. 2005. Antagonistic actions of ecdysone and insulins determine final size in Drosophila. Science 310: 667-670.

Daish, T.J., Cakouros, D., and Kumar, S. 2003. Distinct promoter regions regulate spatial and temporal expression of the Drosophila caspase Dronc. Cell Death Differ. 10: 1348-1356.

Grosshans, H., Johnson, T., Reinert, K.L., Gerstein, M., and Slack, F.J. 2005. The temporal patterning microRNA let-7 regulates several transcription factors at the larval to adult transition in C. elegans. Dev. Cell 8: 321-330.

Grun, D., Wang, Y.L., Langenberger, D., Gunsalus, K.C., and Rajewsky, N. 2005. microRNA target predictions across seven Drosophila species and comparison to mammalian targets. PLoS Comput. Biol. 1: e13. doi: 10.1371/journal. pcbi.0010013.

Hayes, G.D. and Ruvkun, G. 2006. Misexpression of the Caenorhabditis elegans miRNA let-7 is sufficient to drive developmental programs. Cold Spring Harb. Symp. Quant. Biol. 71: 21-27.

Hu, S., Fambrough, D., Atashi, J.R., Goodman, C.S., and Crews, S.T. 1995. The Drosophila abrupt gene encodes a BTB-zinc finger regulatory protein that controls the specificity of neuromuscular connections. Genes \& Dev. 9: 2936-2948.

Jones, M.E. and Schwartz, L.M. 2001. Not all muscles meet the same fate when they die. Cell Biol. Int. 25: 539-545.

Kimura, K.I. and Truman, J.W. 1990. Postmetamorphic cell death in the nervous and muscular systems of Drosophila melanogaster. J. Neurosci. 10: 403-411.

Lagos-Quintana, M., Rauhut, R., Yalcin, A., Meyer, J., Lendeckel, W., and Tuschl, T. 2002. Identification of tissue-specific microRNAs from mouse. Curr. Biol. 12: 735-739.

Lall, S., Grun, D., Krek, A., Chen, K., Wang, Y.L., Dewey, C.N., Sood, P., Colombo, T., Bray, N., Macmenamin, P., et al. 2006. A genome-wide map of conserved microRNA targets in C. elegans. Curr. Biol. 16: 460-471.

Lee, C.Y., Wendel, D.P., Reid, P., Lam, G., Thummel, C.S., and Baehrecke, E.H. 2000. E93 directs steroid-triggered programmed cell death in Drosophila. Mol. Cell 6: 433-443.

Lin, S.Y., Johnson, S.M., Abraham, M., Vella, M.C., Pasquinelli, A., Gamberi, C., Gottlieb, E., and Slack, F.J. 2003. The C. el- egans hunchback homolog, hbl-1, controls temporal patterning and is a probable microRNA target. Dev. Cell 4: 639-650.

Lytle, J.R., Yario, T.A., and Steitz, J.A. 2007. Target mRNAs are repressed as efficiently by microRNA-binding sites in the 5 UTR as in the 3' UTR. Proc. Natl. Acad. Sci. 104: 9667-9672.

McBrayer, Z., Ono, H., Shimell, M., Parvy, J.P., Beckstead, R.B., Warren, J.T., Thummel, C.S., Dauphin-Villemant, C., Gilbert, L.I., and $\mathrm{O}^{\prime}$ Connor, M.B. 2007. Prothoracicotropic hormone regulates developmental timing and body size in Drosophila. Dev. Cell 13: 857-871.

Moss, E.G. 2007. Heterochronic genes and the nature of developmental time. Curr. Biol. 17: R425-R434.

O'Farrell, F., Esfahani, S.S., Engstrom, Y., and Kylsten, P. 2008. Regulation of the Drosophila lin-41 homologue dappled by let-7 reveals conservation of a regulatory mechanism within the LIN-41 subclade. Dev. Dyn. 237: 196-208.

Pasquinelli, A.E., Reinhart, B.J., Slack, F., Martindale, M.Q. Kuroda, M.I., Maller, B., Hayward, D.C., Ball, E.E., Degnan, B., Muller, P., et al. 2000. Conservation of the sequence and temporal expression of $1 e t-7$ heterochronic regulatory RNA. Nature 408: 86-89.

Reinhart, B.J., Slack, F.J., Basson, M., Pasquinelli, A.E., Bettinger, J.C., Rougvie, A.E., Horvitz, H.R., and Ruvkun, G. 2000. The 21-nucleotide let-7 RNA regulates developmental timing in Caenorhabditis elegans. Nature 403: 901-906.

Rougvie, A.E. and Ambros, V. 1995. The heterochronic gene lin-29 encodes a zinc finger protein that controls a terminal differentiation event in Caenorhabditis elegans. Development 121: 2491-2500.

Roy, S. and VijayRaghavan, K. 1999. Muscle pattern diversification in Drosophila: The story of imaginal myogenesis. Bioessays 21: 486-498.

Sempere, L.F., Dubrovsky, E.B., Dubrovskaya, V.A., Berger, E.M., and Ambros, V. 2002. The expression of the let-7 small regulatory RNA is controlled by ecdysone during metamorphosis in Drosophila melanogaster. Dev. Biol. 244: 170-179.

Sempere, L.F., Sokol, N.S., Dubrovsky, E.B., Berger, E.M., and Ambros, V. 2003. Temporal regulation of microRNA expression in Drosophila melanogaster mediated by hormonal signals and Broad-Complex gene activity. Dev. Biol. 259: 9-18.

Slack, F. and Ruvkun, G. 1997. Temporal pattern formation by heterochronic genes. Annu. Rev. Genet. 31: 611-634.

Slack, F.J., Basson, M., Liu, Z., Ambros, V., Horvitz, H.R., and Ruvkun, G. 2000. The lin-41 RBCC gene acts in the C. elegans heterochronic pathway between the let-7 regulatory RNA and the LIN-29 transcription factor. Mol. Cell 5: 659-669.

Sokol, N.S., Xu, P., Jan, Y.-N., and Ambros, V. 2008. Drosophila let-7 microRNA is required for remodeling of the neuromusculature during metamorphosis. Genes \& Dev. (this issue) doi: $10.1101 /$ gad.1671708.

Stefani, G. and Slack, F.J. 2008. Small non-coding RNAs in animal development. Nat. Rev. Mol. Cell. Biol. 9: 219-230.

Thummel, C.S. 2001. Molecular mechanisms of developmental timing in C. elegans and Drosophila. Dev. Cell 1: 453-465.

Vella, M.C., Choi, E.Y., Lin, S.Y., Reinert, K., and Slack, F.J. 2004. The C. elegans microRNA let-7 binds to imperfect let-7 complementary sites from the lin-41 3'UTR. Genes \& Dev. 18: 132-137.

Yin, V.P. and Thummel, C.S. 2005. Mechanisms of steroid-triggered programmed cell death in Drosophila. Semin. Cell Dev. Biol. 16: 237-243.

Yin, V.P., Thummel, C.S., and Bashirullah, A. 2007. Down-regulation of inhibitor of apoptosis levels provides competence for steroid-triggered cell death. J. Cell Biol. 178: 85-92.

Yu, H.H. and Lee, T. 2007. Neuronal temporal identity in postembryonic Drosophila brain. Trends Neurosci. 30: 520-526. 


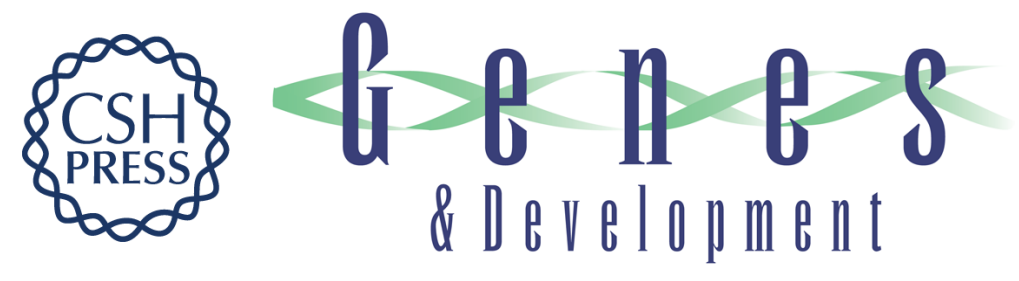

\section{A matter of timing: microRNA-controlled temporal identities in worms and flies}

Manfred Frasch

Genes Dev. 2008, 22:

Access the most recent version at doi:10.1101/gad.1690608
Related Content Drosophila let-7 microRNA is required for remodeling of the neuromusculature during metamorphosis
Nicholas S. Sokol, Peizhang Xu, Yuh-Nung Jan, et al.
Genes Dev. June, 2008 22: 1591-1596
References This article cites 39 articles, 9 of which can be accessed free at:
http://genesdev.cshlp.org/content/22/12/1572.full.html\#ref-list-1
Articles cited in:
http://genesdev.cshlp.org/content/22/12/1572.full.html\#related-urls

\section{License}
Email Alerting
Service
Receive free email alerts when new articles cite this article - sign up in the box at the top right corner of the article or click here.

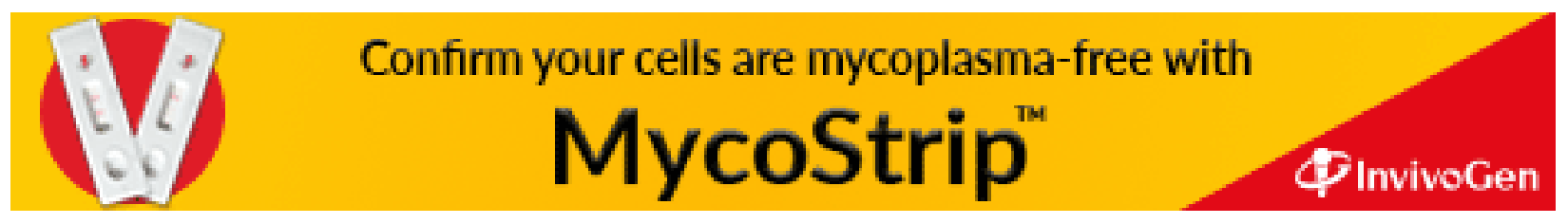

